\title{
An Imbalance Assessment of Coastal Water Supply and Demand in a Highly Populated Area: A System Dynamics Approach
}

\author{
Thuc D. Phan ${ }^{\mathrm{a}}$, James CR. Smart ${ }^{\mathrm{a}}$, Samantha J. Capon ${ }^{\mathrm{a}}$, Wade L. Hadwen a and Oz. Sahin ${ }^{\mathrm{b}}$ \\ a Australian Rivers Institute, Griffith School of Environment, Griffith University, Queensland, Australia \\ ${ }^{b}$ Griffith School of Engineering, Griffith University, Queensland, Australia \\ Email: thuc.phan@griffithuni.edu.au
}

\begin{abstract}
The imbalance of a coastal water supply and demand system is temporally affected by both natural and anthropogenic processes that are interactions between interdependent components with many feedbacks. Water availability is influenced over time by interactions among sea level rise, river flows and salt-water intrusion. Water demand is affected by population growth, agricultural and industrial production. The interactions of these factors will lead to increases or decreases in the imbalance of the coastal water supply and demand over time. Understanding temporal interactions of these drivers and their effects on the imbalance of the coastal freshwater system over time is necessary to improve coastal freshwater management.
\end{abstract}

This study proposes a new approach that applies a system dynamics modelling tool to investigate the imbalance between water supply and demand over time in a highly populated coastal area, Hai Phong, Vietnam. More specifically, this paper investigates the effects of sea level rise, river flows and salinity intrusion on a coastal freshwater availability, together with the effects of population growth, agricultural and industrial production on water demand.

The interrelationships among interdependent variables causing the imbalance of the coastal water supply and demand system are depicted by a "Drifting goals" system archetype with two balancing loops. Both two goal seeking loops (B1 and B2) are capable of relieving the imbalance of the system. However, the goal seeking loop B1 generally takes more time and efforts to achieve a goal than the goal seeking loop B2. This conception plays an important role for stakeholders in identifying management interventions for the coastal freshwater system. A preliminary imbalance model of the coastal water supply and demand system was developed. The key data requirements and equations for calibration and simulation of the model were also initially identified.

A number of methods will be used to reduce uncertainties inherent in, and validate the performance of the models. The uncertainties associated with climatic and socio-economic unpredictability will be reduced by developing a range of scenarios of sea level rise, river flow, and domestic use, agricultural and industrial production. The validity of the models will be calibrated by using expert and stakeholder judgements, historical data, previous hydrodynamic studies, and field measurements of river flows and salinity in the study area.

This study has a high potential for novelty as it incorporates both climatic and non-climatic drivers into one framework to assess the imbalance between coastal water supply and demand in a developing country. More specifically, it will provide an understanding of the present and future imbalance of a water supply and demand system in highly populated coastal areas with a high rate of urbanization and population growth, together with sea level rise and precipitation decrease. This study will directly contribute to the development of collective and decisive adaptation actions that aim to secure efficient freshwater resources for the socioeconomic development in the port city of Hai Phong, Vietnam.

Keywords: $\quad$ Land use change, population growth, river flow, salinity, sea level rise 


\section{INTRODUCTION}

Water resources management faces many challenges. Population growth, urbanization, and economic development, in addition to the existing degree of exploitation, are widely considered to be the main factors contributing to a growing gap between water supply and demand in many places around the world (Miller \& Belton, 2014). This issue is especially prevalent in coastal areas of developing countries, where high rates of population growth and urbanization are likely to result in severe water scarcity. All of these issues are being exacerbated by climate change, and particularly sea level rise, and changes to precipitation that are altering patterns of river discharge as well as saltwater intrusion into estuaries (Nguyen et al., 2008). Consequently, coastal freshwater systems in developing countries are being affected by the interactions among these drivers.

Coastal water supply and demand systems involve complex natural and anthropogenic processes that are interactions between interdependent components with many feedbacks. Water availability is affected by climate variability and climate change. For example, changes in sea level and river flows over time probably lead to salinity intrusion (Nguyen et al., 2008) and thus influence variability in water availability. Population growth and land use change also affect water demand via changing water consumption over time. As a whole, the vulnerability of water resources systems over time is affected by changes in the condition of the main drivers. Thus, it is crucial to examine temporal variations to understand the interactions of interdependent elements on the imbalance of coastal water supply and demand systems.

Moreover, dynamically simulating a water supply and demand system is likely to provide greater understanding of system vulnerability to climatic and non-climatic changes. A holistic understanding of the temporal interactions of interdependent elements in the systems leads to more effective learning and management in complex systems (Winz et al., 2009), as well as consensus building for identifying robust adaptation options which could deal with both current and future conditions (Fussel, 2007). It is appropriate, therefore, to apply a system dynamics approach to the water supply and demand system that takes the dynamic character of these systems into account (Sahin et al., 2014) to help decision makers understand the complex system and initiate better management strategies.

The use of system dynamics approach for water resources management has emerged in the past two decades (Winz et al., 2009) and the approach has proven useful for providing valuable insights into problems and systems' long-run behaviour at the strategic level (Mirchi, 2013). More specifically, the system dynamics approach is a highly appropriate strategic water supply and demand modelling tool since it provides an understanding of the dynamic, complex and multi-dimensional nature of water supply and demand management which can be used for forecasts, infrastructure planning, demand planning, revenue and expenditure estimation (Stave, 2003; Sahin et al., 2014). System dynamics software enables modellers to use insights learned from hydrologic studies and then model the relationship between the hydrologic system and other aspects of the system such as socio-economic development and other non-physical parameters of the system (Beall et al., 2011) which can then be incorporated into one comprehensive model. This allows numerous scenarios to be explored through an adjustable dashboard display (Sahin et al., 2014).

Although, the system dynamics approach has also been applied in the management of water supply and demand systems around the world (Stave, 2003; Dai et al., 2013; Sahin et al., 2014), few studies have applied this approach for the adaptation of water resources management to climate change (Dawadi \& Ahmad 2013). Therefore, this paper proposes a new approach that applies the system dynamics modelling tool to investigate the imbalance between water supply and demand in a highly populated coastal area, Hai Phong, Vietnam. More specifically, this paper assesses the effects of sea level rise, river flows and salinity intrusion on a coastal freshwater availability, and also explores the impacts of socio-economic drivers such as population growth, agricultural and industrial production on water demand.

\section{METHODOLOGY}

\subsection{Study area}

Hai Phong is a coastal urban area in the Red River Delta in the North of Vietnam (Figure 1). It covers an area of $1,527 \mathrm{~km}^{2}$ with a resident population of about 1.9 million people and an average population density of 1,580 people $/ \mathrm{km}^{2}$ (HPSYB, 2013). High rates of industrialization and urbanization are leading to water shortages which could threaten the city's socio-economic development. This issue is being exacerbated by sea level rise and precipitation decline which are altering patterns of river flow and increasing saltwater intrusion in estuaries, thereby affecting freshwater availability. Consequently, there is an imbalance between water supply and demand which is affecting the socio-economic development of the port city.

The topographic relief of estuaries in Hai Phong city is relatively low, around $1-1.5 \mathrm{~m}$ of sea level, and thus tidal conditions occur. Seasonal hydrological patterns depend, therefore, on seasonal river flows and tidal stage. The highest monthly sea level occurs between November and January and the lowest level occurs 
between March and April. However, the highest monthly river flow happens between July and August, and the lowest between December and April. Consequently, saltwater intrusion into freshwater zones occurs between December and April, especially in dry seasons (from last December to February), exacerbating water shortage in the port city.

\subsection{Causal loop diagrams}

A causal loop diagram for a coastal water supply and demand system (Figure 2) provides a comprehensive conception of the imbalance in a coastal freshwater system. The imbalance of this system is influenced by changing water supply and demand over time.

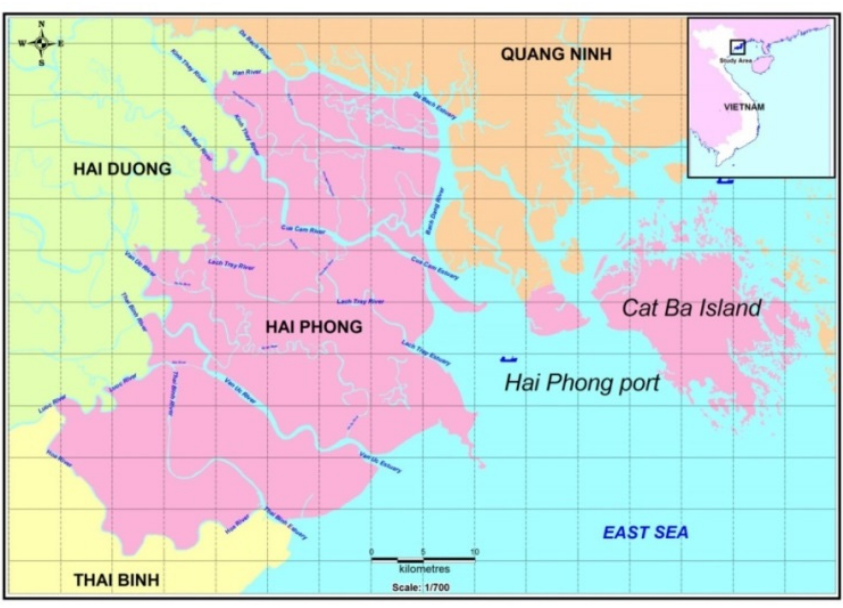

Figure 1. Hai Phong city - a case study location. Water supply is driven by sea level rise, river flows, precipitation, salinity intrusion and sluice gate capacity. Precipitation and river flows are the main sources of water supply. However, water supply is limited by salinity intrusion which is driven by interactions between sea level rise and river flow decrease. Water supply is also constrained by the sluice gate system as it controls freshwater and salinity intrusion from main rivers to their distributaries, which provide freshwater directly to all activities of the port city. Water demand is driven by domestic use, agricultural and industrial production. Interactions between these factors lead to increases or decreases in the system's imbalance over time.

The imbalance of the coastal freshwater system is illustrated by two balancing loops (B1 and B2). The B1 loop reveals the relationship between water supply and imbalance, and the B2 loop illustrates the relationship between water demand and imbalance. In this context, the imbalance is defined as demand outweighing supply. The lower water supply, the greater is the system's imbalance for a given level of demand. However, water demand is inversely related to this imbalance, such that the greater water demand, the greater is the system's imbalance.

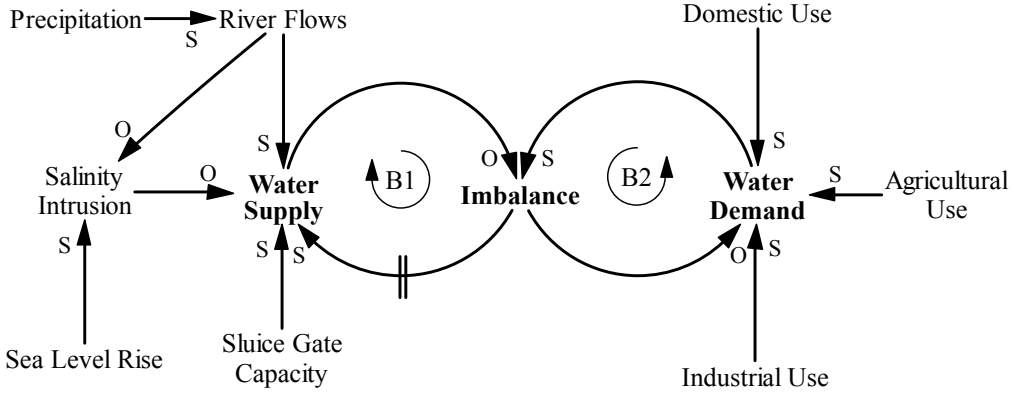

Figure 2. The relationships among key elements and the feedback loops. Legend: $S$ (same direction), $O$ (opposite direction), B (balancing loop), $\neq$ (delay)

The interactions of these two feedback loops create the "Drifting goals" system archetype (Maani and Cavana, 2007). This archetype begins with a standard goal seeking loop B1 which attempts to increase water supply via some actions for relieving the imbalance. However, there is a difficulty that often arises because of the delay associated with taking more time and effort to increase water supply. Therefore, a time delay exists between imbalance and water supply. The goal seeking loop B2 is also capable of relieving the imbalance by decreasing the water demand. However, the goal seeking loop B2 is generally easier and takes less time than the goal seeking loop B1. This conception plays an important role in identifying management interventions for the coastal freshwater system.

\subsection{System boundary and elements}

The coastal water supply and demand is affected by both climatic and non-climatic drivers. Thus, it is necessary to examine simultaneously the effects of both types of drivers. Identifying the most important factors of the system is an important step as modelling all components and their interactions in the system is not possible within the constraints of the current project. Essential variables for simulation were chosen based on a review of the local context and an analysis of the historical data related to coastal water supply and demand. In addition, variables were also identified by reviewing the world literature for more generic variables and the typical level of their effects on coastal water supply and demand systems. The most important variables, identified through these approaches, were incorporated into the system dynamics model for assessing the system's imbalance (Figure 3). 
Two sub-models: a dry season model and a rainy season will be simulated to reflect the seasonal change and difference in water supply and demand. The time step is the time interval for the simulation: $d t=0.25$ year. Units for time are the unit of measure of time: year. The Vensim DSS software (Ventan System.inc) will be used to run the dynamic models.

\subsection{Scenarios development for imbalance assessment}

Uncertainties about future climatic and non-climatic changes make it challenging to accurately assess the imbalance of the coastal freshwater

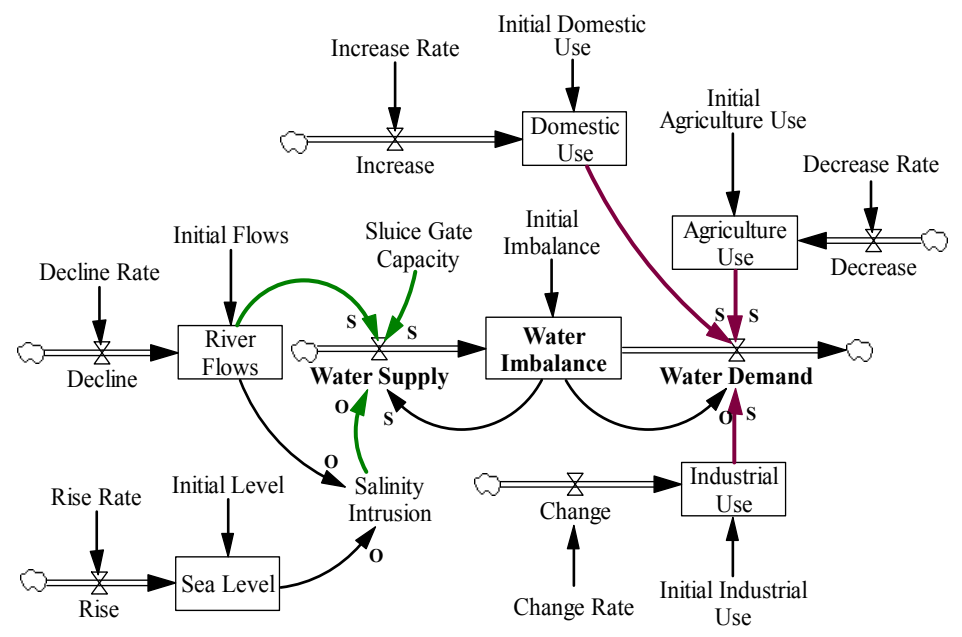

Figure 3. Stocks, flows and variables in the dynamics model. system. Developing scenarios is a suitable way to address these uncertainties. Scenarios are useful for robust decision making in the case of complex problems with deep uncertainty, such as long-term water management under changing conditions (Haasnoot \& Middelkoop, 2012). Scenarios should cover a broad range of possible futures and uncertainties, especially regarding the extreme events (Lempert et al., 2006) and consider the dynamic interactions among climatic and non-climatic drivers in the course of time which could influence the performance of adaptation options (Haasnoot \& Middelkoop, 2012).

\section{- Sea level rise scenarios}

Sea level rise projections conducted by Ministry of Natural Resource and Environment (MONRE), based on the IPCC Scenarios: B1, B2 and A1F1 for Hai Phong area in 2100 are as follows: For scenario B1 projected sea level rise was 42 to $57 \mathrm{~cm}$. For scenario B2 projected sea level rise was 49 to $64 \mathrm{~cm}$. The scenario A1F1 was 66 to $85 \mathrm{~cm}$. The range of mean sea level rise for the area under these three scenarios was $42 \mathrm{~cm}$ to 85 $\mathrm{cm}$ in 2100. In the past 50 years, sea level at Hon Dau station in Hai Phong area rose about 20cm (MONRE, 2012). Therefore, in this study, a range of sea level rise from $15 \mathrm{~cm}$ to $45 \mathrm{~cm}$ is used to develop three sea level rise scenarios: $15 \mathrm{~cm}, 30 \mathrm{~cm}$ and $45 \mathrm{~m}$ in the year of 2050 .

\section{- River flow scenarios}

River flow scenarios in Hai Phong city will be developed based on the historical data for four rivers: Van Uc River, Kinh Thay-Cam River, Thai Binh River and Lach Tray River. The total annual, dry and rainy seasonal flows of these rivers are 42.456 billion $\mathrm{m}^{3}, 12.206$ billion $\mathrm{m}^{3}$ and 30.270 billion $\mathrm{m}^{3}$ respectively (NMWS, 2014). The historical data series of flows for the Van Uc and Kinh Thay - Cam River which have the largest flows in Hai Phong city, accounts for 79\% of four rivers are available from 2000 to 2013. Therefore, these data will be used to develop scenarios. The flows of these two rivers declined by $1.27 \%$ per year from 2000 to 2013 . Accordingly, a range of annual river flow decrease from $3 \%$ to $7 \%$ will be used to develop three river flow decrease scenarios: $3 \%, 5 \%$ and $7 \%$ in the period of 50 years.

\section{- Domestic use scenarios}

The population of Hai Phong city in the main land was about 1.89 million in 2013 , and the growth rate of population for the 14 years from 2000 to 2013 was an average of 1\%. The Vietnam standard for the first city as Hai Phong reports that the water consumption for urban and rural residential uses is estimated as 165L/person/day and 120L/person/day respectively (MOC, 2006). However, a study by Department of Agricultural and Rural Development in 2014, the actual water use for urban and rural areas in Hai Phong city was calculated as 130L/person/day and 60L/person/day respectively (DARD, 2014). In addition, this study based on the IPCC scenarios B1, B2 and A2 estimated that per capita water consumption for urban and rural residents by 2020 will be $150 \mathrm{~L} /$ person/day and $80 \mathrm{~L} /$ person/day respectively. These data when considered together with the effects of water price, income and weather factors on per capita water consumption, a range of capita water consumption increases from $2 \%$ to $6 \%$ will be used to develop three scenarios: $2 \%, 4 \%$ and $6 \%$ increases in domestic water use over the period of 50 years.

\section{- Agricultural use scenarios}

Water demand for agricultural uses includes irrigation, livestock and freshwater aquaculture uses. The water consumption for each section will be calculated based on the irrigation area, aquaculture area and livestock numbers over the 14 year period, from 2000 to 2013 of Yearly Statistic Books in Hai Phong city, and water consumption estimates from a study by the Department of Agriculture and Rural Development in 2014. In 
this study, the water consumption was estimated for irrigation (spring paddy: $5850 \mathrm{~m}^{3} / \mathrm{ha} / \mathrm{year}$; winter paddy: $4935 \mathrm{~m}^{3} /$ ha/year; other annual crop: $1529 \mathrm{~m}^{3} /$ ha/year; perennial crop: $2533 \mathrm{~m}^{3} / \mathrm{ha} /$ year), for livestock (buffalo and cows: 135L/individual/day; pig: 60L/individual/day; chicken: 11L/individual/day), for aquaculture (freshwater aquaculture: $13336 \mathrm{~m}^{3} / \mathrm{ha} /$ year; blackish water aquaculture: $46589 \mathrm{~m}^{3} / \mathrm{ha} /$ year). These data, coupled with considering the effects of weather factors on agricultural production will be used to develop scenarios. A range of agricultural water use reductions ranging from $1 \%$ to $5 \%$ will be used to construct three scenarios: $1 \%, 3 \%$ and $5 \%$ decrease over a 50 year period.

\section{- Industrial scenarios}

The Industrial sector in Hai Phong city comprises three main categories: industrial zone, small industrial complex and enterprise. The water consumption for each category will be calculated based on the number of these categories recorded historically over a period of 10 years from 2004 to 2014 in a study by the Department of Industry and Trade in 2013. According to the Vietnam standard, water consumption for the production of beer, wine, milk, food and garment production is estimated as $45 \mathrm{~m}^{3} / \mathrm{ha} / \mathrm{day}$, and for other productions is estimated to be $22 \mathrm{~m}^{3} / \mathrm{ha} / \mathrm{day}$. In addition, a study by the Department of Agricultural and Rural Development in 2014, the water consumption for industrial production was estimated based on size and concentration as follows: $45 \mathrm{~m}^{3} / \mathrm{ha} /$ day for the industrial zone, $30 \mathrm{~m}^{3} / \mathrm{ha} /$ day for the small industrial complex, and $10 \%$ of domestic use for the small enterprise in rural areas. These data will be used to develop a range of industrial water consumption increase from $0 \%$ to $4 \%$ with three scenarios: $0 \%, 2 \%$ and $4 \%$ increase over a 50 year period.

\subsection{Model components}

\section{- Water supply component}

The water supply component will include the temporal interactions of sea level rise, river flows and salinity intrusion. Sea level rise and river flow, which are two important factors in the system, drive other model elements in the system. These variables can be altered under different scenarios to explore the effects of sea level rise and river flow decrease on the other model elements, especially the availability of freshwater for supply purposes. The sea level and river flow at a given time $t$ and each time step $d t$, are calculated using the following equations:

$$
S L(t)=\int_{0}^{t} R R x d t+I S L
$$

Where SL ( $\mathrm{t}$ ) is Sea level at time t, RR is the Rise Rate at each time step $d t$, ISL is the Initial Sea Level at the beginning of a simulation.

$$
R F(t)=\int_{0}^{t} D R x d t+I R F
$$

$\mathrm{RF}(\mathrm{t})$ is River Flow at time $t$, DR is Decline Rate for each time step $d t$, and IRF is the Initial River Flow at the beginning of a simulation.

Monte Carlo Simulations will be used to investigate the relationships between sea level and river flow that cause salinity intrusion into water supply through a different range of sea level rise and river flow decrease.

\section{- Water demand component}

The water demand component includes domestic uses, agricultural uses and industrial uses. A water demand for agricultural uses, domestic uses and industrial uses at a given time $t$, is calculated from the following equations.

$$
A U(t)=\int_{0}^{t} D R x d t+I A U
$$

where AU is Agricultural Uses at given time t, IAU is Initial Agricultural Use, DR is Decreasing Rate at each time step $d t$, IAA is Initial Agricultural Use at the beginning of simulation.

$$
D U(t)=\int_{0}^{t} I R x d t+I D U
$$

where DU is Domestic Uses at time t, IR is Increase Rate at each time step $d t$, IDU is Initial Domestic Uses at the beginning of simulation.

$$
I U(t)=\int_{0}^{t} C R x d t+I I U
$$

where IU is Industrial Uses at time t, CR is Change Rate at each time step $d t$, IIU is Initial Industrial Use at the beginning of simulation.

$$
W D(t)=(A U(t)+D U(t)+I U(t))
$$

where WD is Water Demand at time t, AU, DU and IU is Agricultural Uses, Domestic Uses, and Industrial Uses at time $t$. 
Finally, the Water Imbalance between Water Supply and Demand at a given time $t$, is calculated as following equations.

$$
W I(t)=[W S(t)-W D(t)]
$$

where WI is Water Imbalance at time $t$, WS is Water Supply at time t, WD is Water Demand at time t.

\section{MODEL VALIDATION AND UNCERTAINTY TREATMENT}

Adequate treatment of uncertainties plays a crucial role in model development and it is important for research models to incorporate the potentially critical influence of such uncertainties on assessments. In this study, uncertainties may arise from future climate change, population growth, water consumption trends and land use change. A range of scenarios of sea level rise, river flows, domestic use, agricultural and industrial use will be developed to reduce these uncertainties associated with climatic and socio-economic unpredictability. These scenarios are built based on a range of historical data and ensembles of climate change projections at regional and local scales. The essential variables in the conceptual models of the water supply and demand system are clearly identified by analysing the local context and reviewing the world literature to reduce the structural uncertainty. The uncertainty of value will be evaluated by statically analysing the observations of sea level rise, river flows, salinity and land use change, and population growth.

The validity of the models will be calibrated by using several methods, including; expert and stakeholder judgements, historical data, previous hydrodynamic studies and field measurements. The preliminary models will be advised by water managers, climate change experts and stakeholders through several workshops in Hai Phong city. In addition, collected historical data on sea level rise (from 1972 to 2013), river flows (from 2001 to 2013), salinity (from 1997 to 2013), population growth (from 2008 to 2013), and land use change (from 2005 to 2013) will be used to calibrate the models. The previous study results on estuarine hydrodynamic regime (Nguyen et al., 2013), and on salinity intrusion due to sea level rise (Nguyen and Umeyama, 2011), in the Red and Thai Binh river system will be also used to validate the models. In addition, the field measurements on salinity and river flows at Van Uc, Cam and Lach Tray estuary in dry season will be conducted by using a method described by Savenije (1992) to understand the relationships between river flow and salinity intrusion.

\section{DISCUSSION AND CONCLUSION}

This research aims to provide a dynamic framework for assessing the imbalance between water supply and demand in a highly populated coastal area in a developing country in relation to a range of climatic and nonclimatic scenarios. More specifically, this framework will enable stakeholders to understand the effects of interactions of sea level rise, river flows and salinity intrusion on coastal freshwater availability, and of population growth, agricultural and industrial production on water demand such that appropriate and robust adaptation strategies can be identified.

Determining a system structure, including positive and negative relationships between variables, feedback loops and delays is the first step in every system dynamics projects (Sterman, 2000). The system structure is then analysed to identify system archetypes, which are essential for understanding the common dynamic processes that characterize the behaviour of the system (Sterman, 2000; Maani and Cavana, 2007). Analysing system archetypes can often help to identify system leverage points in the systems (Senge, 2006). The leverage points are those locations at which an intervention should have the most influence on the system behaviour (Maani and Cavana, 2007). Each archetype has its leverage point where an intervention strategy could be proposed to improve the situation of systems. These steps have been proven to be applicable for developing a comprehensive understanding and optimizing water resources management (Mirchi, 2013).

A preliminary model of the imbalance with stocks, flows and variables, and their interrelationships between water supply and demand in the system dynamics model was developed. Key data requirements and equations for the model were initially collected and developed. However, the model's outcome has not been achieved at this stage as with a hope of receiving comprehensive advices from local water managers, climate change experts and stakeholders through several workshops in Hai Phong city for a feasible and robust academic study.

This study has a high potential for novelty as it incorporates both climatic and non-climatic drivers into one framework to assess the imbalance between water supply and demand in a developing country. More specifically, it provides an understanding of the likely the present and future imbalance between water supply and demand in the highly populated coastal area where there is a high rate of urbanization and population growth, which experiencing sea level rise and precipitation decrease. This study will directly contribute to an action plan for the city that aims to secure efficiently freshwater resources for the port city's socio-economic development into the future. 
Phan et al., An imbalance Assessment of a Coastal Water Supply and Demand in a Highly Populated Area: A System Dynamics Approach

\section{ACKNOWLEDGEMENTS}

This study is funded by Griffith University through a PhD program, and by Economy and Environment Program for Southeast Asia through a project PCO15-0929-003.

\section{REFERENCES}

Beall, A., Fiedler, F., Boll, J., \& Cosens, B. (2011). Sustainable Water Resource Management and Participatory System Dynamics. Case Study: Developing the Palouse Basin Participatory Model. Sustainability, 3(12), 720-742. doi: 10.3390/su3050720

Dai, S., Li, L., Xu, H., Pan, X., \& Li, X. (2013). A system dynamics approach for water resources policy analysis in arid land: a model for Manas River Basin. Journal of Arid Land, 5(1), 118-131. doi: $10.1007 / \mathrm{s} 40333-013-0147-1$

DARD. (2014). Reviewing, adjusting and supplementing the planning of irrigation systems in Hai Phong until 2020, vision to 2030: Department of Agricultural and Rural Development.

Dawadi, S., \& Ahmad, S. (2013). Evaluating the impact of demand-side management on water resources under changing climatic conditions and increasing population. Journal of Environmental Management, 114, 261-275. doi: 10.1016/j.jenvman.2012.10.015

DONRE. (2010). Scenarios for climate change and sea level rise for Hai Phong. Hai Phong, Vietnam: Department of Natural Resources and Environmental Management.

Fisher, D. M. (2007). Modeling Dynamic Systems: Lessons for a First Course, 2nd edition: Isee systems, Inc.

Füssel, H. M. (2007). Adaptation planning for climate change: concepts, assessment approaches, and key lessons. Sustainability Science, 2(2), 265-275. doi: 10.1007/s11625-007-0032-y

Haasnoot, M., \& Middelkoop, H. (2012). A history of futures: A review of scenario use in water policy studies in the Netherlands. Environ Sci Policy, 19-20(6), 108-120. doi: 10.1016/j.envsci.2012.03.002

Lempert, R., Groves, D., Popper, S., \& Bankes, S. (2006). A general, analytic method for generating robust strategies and narrative scenarios. Management Science, 50(4), 514-528.

Maani KE, Cavana RY. (2007). Systems Thinking, System Dynamic: Managing Change and Complexity, 2 edn, Prentice Hall, Auckland.

Miller, K. A., \& Belton, V. (2014). Water resource management and climate change adaptation: a holistic and multiple criteria perspective. Mitigation and Adaptation Strategies for Global Change, 19(3), 289-308. doi: 10.1007/s11027-013-9537-0

Mirchi, A. (2013). System dynamics modeling as a quantitative-qualitative framework for sustainable water resources management: Insights for water quality policy in the great lakes region. (Doctor of Philosophy ), Michigan Technological University, America.

MONRE. (2012). Scenarios for climate change and sea level rise for Vietnam. Hanoi, Vietnam: Pulishing House of Natural Resources, Environment and Map of Vietnam.

MOC. (2006). TCXDVN 33:2006-Water Supply - Distribution System and Facilities Design Standard: Ministry of Construction.

Nguyen, A. D., Savenije, H. H. G., Pham, D. N., \& Tang, D. T. (2008). Using salt intrusion measurements to determine the freshwater discharge distribution over the branches of a multi-channel estuary: The Mekong Delta case. Estuarine, Coastal and Shelf Science, 77(3), 433-445. doi: 10.1016/j.ecss.2007.10.010

Nguyen, D., \& Umeyama, M. (2011). Saline Intrusion due to the Accelerative Sea Level in the Red River System in Vietnam. Paper presented at the World Environmental and Water Resources Congress 2011: Bearing Knowledge for Sustainability.

Nguyen, Q. M., Ngo, L. L., \& Dao, D. C. (2013). An assessment of hydrodynamic regime in estuaries of Red and Thai Binh river system. Water Resources and Environmental Engineering, 11, 63-72.

Sahin, O., Siems, R. S., Stewart, R. A., \& Porter, M. G. (2014). Paradigm shift to enhanced water supply planning through augmented grids, scarcity pricing and adaptive factory water: A system dynamics approach. Environmental Modelling \& Software. doi: 10.1016/j.envsoft.2014.05.018

Stave, K. A. (2003). A system dynamics model to facilitate public understanding of water management options in Las Vegas, Nevada. Journal of Environmental Management, 67(4), 303-313. doi: 10.1016/s0301-4797(02)00205-0

Senge PM. (2006). The Fifth Discipline; the Art and Practice of the Learning Organization. Doubleday: New York, London, Toronto, Sydney, Auckland.

Sterman JD. (2000). Business Dynamics: System Thinking and Modelling for A Complex World. Irwin McGraw-Hill: New York.

Winz, I., Brierley, G., \& Trowsdale, S. (2009). The use of system dynamics simulation in water resources management. Water Resource Management, 23, 1301-1323. doi: 10.1007/s11269-008-9328-7 